from country to country that a single pattern of legislation is not feasible on a world-wide basis".

A somewhat different aspect of food quality is discussed in No. 24l of the World Health Organization Technical Report Series $\dagger$. This publication stresses that the world scarcity of protein makes it necessary to conserve and utilize meat supplies to the fullest possible extent. This requires the application of a meat hygiene system which includes supervision of the meat production chain from the farm, through transport to a well-run abattoir, to distribution to the

$\dagger$ World Health Organization. WHO Technical Report Series, No. 241, and/or FAO Agricultural Studies, No, 58: Joint FAO/WHO Expert Committee on Meat Hygiene-Second Report. Pp. 88. (Geneva World Health Organization; London: H.M. Stationery Office, 1962. 3 Swiss francs; 5 s.; 1 dollar. consumer. This booklet covers each of these stages separately, for example, diseases, slaughter, inspection, refrigeration, transport, marketing, manufacture, sanitation of retail shops and restaurant kitchens, hygiene of handlers, education, newer developments and laboratory methods. A separate section on poultry hygiene is also included. The Committee recommends that the Food and Agriculture Organization and the World Health Organization should encourage further investigation into various problems related to meat hygiene, including those associated with chomical residues, meat-borne diseases, rapid methods for diagnosing organisms and the presence of radionuclides.

D. Pearson

\title{
FISHERIES OF NIGERIA
}

TN an excellent report*, Mr. A. R. Longhurst sums 1 up the fisheries situation in Nigeria and its future requirements. He estimates that at present only some 58,000 out of Nigeria's fish supplies of 203,000 tons are produced locally, the rest being imported, and that, even so, the supply of fish per head of the population is only $11.36 \mathrm{lb}$. per annum. He doubts whether the indigenous sea fisheries, even if improved by some mechanization and other possible developments, will go far to fill the gap; and the small fleet of foreign-owned inshore trawlers has only limited prospects of expansion. Mr. Longhurst thinks that the best prospects lie in the exploitation of distantwater fisheries, both pelagic (especially the tunas) and demersal. But for this much capital and expertise will be needed, and there is especially the need of a deep-water fishing harbour with all the ancillary facilities without which foreign fishing enterprises are unlikely to be able to work from Nigeria.

There is an interesting account of the freshwater fisheries, indicating scope for expansion in the potentially rich fisheries of Lake Chad. Mr. Longhurst summarizes the research and development work that has already been done in Nigeria and West Africa in general, but the picture was not one of sustained effort. There is a very useful bibliography.

* Report on the Fisheries of Nigeria 1961. By A. R. Longhurst. Pp. 53. (Lagos: Federal Fisheries Service, Ministry of Economic Development, 1962.)
In his summary of the hydrographic situation, Mr. Longhurst shows that Nigeria lies in the area between the relatively rich cold water of the Benguela and Canary Currents, and is subject to the warm nutrient-poor Guinea Current. But the big rivers, and especially the Niger, bring down in their annual floods important amounts of organic matter. The great influence of the thermocline in the distribution of the fish is restated.

Based on this summary, Mr. Longhurst describes the research work begun by the Federal Fisheries Service, which has its headquarters at Lagos but can undertake research anywhere in Nigeria, at the request of the regional authorities. There is an establishment of a director and five research officers, a small band for so large a territory with such diverse problems. A 70 -ft. research vessel has been recently acquired, and surveys are being made of the fish and crustacean resources, as well as hydrographic sections and plankton work. Research on fish includes a study of the life-histories of the most important species; in conjunction with studies of mesh-selection and of the fishing effort, it is planned to get the information needed for a rational management of the inshore trawl fisheries.

Those who know how difficult it is to start and carry on such a programme will wish the Federal Fisheries Department well in their important work.

C. F. HICKLING

\section{AMATEUR RADIO ASTRONOMY}

$\mathrm{R}$ ADIO astronomy has attracted to itself a band of amateurs no less zealous than those who are devoted to optical astronomy. The techniques required for the simplest observations are more complex than those required to build a small optical telescope and most of the work done so far has necessarily been by groups of amateurs who have combined resources and experience to build aerials and receivers and have worked together on the assessment of observations. The Radio Electronics Section of the British Astronomical Association has co-ordinated this work and has recently published a mernoir on "Radio Astronomy and Radio Telescopes" (40, No. 1; 1962 February) edited by Dr. J. Heywood.

This memoir sets out to provide a useful introduction for a beginner to the techniques of radio astronomy. A helpful description is given of theoretical and practical fundamentals of the aerial and receiver design of the basic installation necessary for amateur observations.
An encouraging aspect of amateur interest in radio astronomy in Great Britain is its youth. Six of the contributors to the memoir were under twenty-one when they wrote their articles. Two of these were sixth-form schoolboys who wrote their contribution on the physical principles of radio wave propagation and reception. A recent publication in the Journal of the British Astronomical Association $(72,19 ; 1962)$ describes work by another sixth-form student, J. K. Sabbagh, on "An Analysis of Extraterrestrial Records at $27 \mathrm{Mc} / \mathrm{s}$ ".

Many types of observation are possible with simple receivers. These include observations of the strong radio sources with interferometers and the effects of the ionosphere on the incoming signals; the Sun and Jupiter can be studied for their variability. The professional radio astronomer heartily encourages this field of amateur activity.

R. D. Davies 